\title{
The European Association for Palliative Care basic dataset to describe a palliative care cancer population: Results from an international Delphi process
}

Palliative Medicine

20I4, Vol. 28(6) 463-473

(C) The Author(s) 2014

Reprints and permissions:

sagepub.co.uk/journalsPermissions.nav DOI: 10.1 I77/02692।63|4521264

pmi.sagepub.com

@SAGE

\author{
Katrin R Sigurdardottir 1,2,3, Stein Kaasa 1,4, Jan H Rosland ${ }^{2,5}$, \\ Claudia Bausewein ${ }^{6,7}$, Lukas Radbruch ${ }^{8,9}$ \\ and Dagny F Haugen ${ }^{1,3}$; on behalf of PRISMA
}

\begin{abstract}
Background: One of the barriers identified in palliative care research is the lack of common criteria to describe the population. Aim: The aim of this Delphi process was to obtain consensus on a basic set of core variables to describe or classify a palliative care cancer population.

Design and setting: This was a five-step international Delphi exercise. A total of II7 experts were invited to participate. Based on a literature review and analyses of existing minimum datasets for national databases, a list of 18 proposed variables was presented in the first Delphi round. The two first rounds focused on which variables to include, and several new variables were proposed. The three last Delphi rounds focused on how the agreed variables should be recorded. Consensus was defined as at least $70 \%$ agreement.

Results: A total of 64 experts from 30 countries participated. High consensus was reached on 31 variables, divided between a 'patient form' - date of birth, gender, living situation, education, ethnicity and I 2 symptoms - and a 'health-care personnel form' - patient's date of birth, principal diagnosis, date of the principal diagnosis, stage of the cancer disease, site of metastases, present anticancer treatment, main additional diagnoses, stage of the additional diagnoses, medication, weight loss, performance status, cognitive impairment, place of care and provision of care. It was more difficult to agree upon how to record the variables, but consensus was reached on all except ethnicity, vomiting and weight loss.
\end{abstract}

Conclusion: Consensus was reached on a set of core variables and how they should be recorded.

\section{Keywords}

Palliative care, Delphi technique, patients, database, demography

\section{What is already known about the topic?}

- Standards are lacking on how to describe palliative care cancer populations in research, and very few descriptors are consistently used.

- Generalizability of study results is a major challenge in palliative care research.

'European Palliative Care Research Centre, Department of Cancer Research and Molecular Medicine, Faculty of Medicine, Norwegian University of Science and Technology (NTNU), Trondheim, Norway

${ }^{2}$ Sunniva Centre for Palliative Care, Haraldsplass Deaconess Hospital, Bergen, Norway

${ }^{3}$ Regional Centre of Excellence for Palliative Care, Western Norway, Haukeland University Hospital, Bergen, Norway

${ }^{4}$ Department of Oncology, St. Olavs Hospital, Trondheim University Hospital, Trondheim, Norway

${ }^{5}$ Department of Clinical Medicine, University of Bergen, Bergen, Norway
6Department of Palliative Care, Policy and Rehabilitation, Cicely Saunders Institute, King's College London, London, UK

${ }^{7}$ Department for Palliative Medicine, University Hospital Munich, Munich, Germany

${ }^{8}$ Department of Palliative Medicine, University of Bonn, Bonn, Germany ${ }^{9}$ European Association for Palliative Care (EAPC), Milan, Italy

\section{Corresponding author:}

Katrin R Sigurdardottir, European Palliative Care Research Centre, Faculty of Medicine, Norwegian University of Science and Technology (NTNU), Bevegelsessenteret Etg 3 Øst, St. Olavs Hospital, N-7006

Trondheim, Norway.

Email: katrin.sigurdardottir@haraldsplass.no 


\section{What this paper adds?}

- This paper presents the first internationally anchored basic dataset for reporting patient characteristics and medical variables in palliative care cancer research.

Implications for practice, theory or policy?

- The EAPC basic dataset of patient characteristics and medical variables gives a unique platform for standardizing research reporting, and a common framework for researchers, clinicians, and other palliative care stakeholders

- The EAPC basic dataset can be used as a basis for national and international databases, supplemented by relevant quality indicators

\section{Introduction}

Whom is the study about? This is one of the key questions readers ask themselves when reading an article. A clear description of the patient population is the only way to answer this question and allow the readers to judge whether the results are applicable to their own clinical setting. Describing the population in sufficient detail is a prerequisite for generalizing study findings or comparing results across trials.

External validity, that is, generalizability of study results, is a major challenge in palliative care research. Palliative care populations may differ extensively with respect to age, diagnoses, symptom burden, functional status and survival. ${ }^{1,2}$ As a consequence, all relevant information should be included when reporting on a palliative care study sample. The need to standardize this reporting has been recognized by several authors. ${ }^{3-7}$

The project 'PRISMA', funded by The European Commission's Seventh Framework Programme, delivered an integrated programme to coordinate research priorities and practice in end-of-life care, defined as care in the last year of life. ${ }^{8}$ As part of PRISMA, the first comprehensive survey of end-of-life cancer care research in Europe was conducted, mapping research activities and priorities. ${ }^{9}$ The survey results were further explored in a workshop aiming to identify barriers to end-of-life care research and look for solutions to overcome the barriers and strengthen the research. The workshop identified the lack of consensus on common definitions, outcomes, and methodology as a major research barrier. ${ }^{10}$ Based on this result, the European Palliative Care Research Centre (PRC) ${ }^{11}$ in collaboration with the European Association for Palliative Care Research Network (EAPC-RN) ${ }^{12}$ started a process to develop and reach consensus on a basic set of variables to describe a palliative care population.

The work towards a common set of descriptors has been done in two steps. First, a systematic literature review was conducted to explore which variables have been used to characterize adult palliative care cancer populations in randomized controlled trials (RCTs). ${ }^{13}$ Data from 336 included full-text articles confirmed the lack of standards on how to describe the population and showed that very few variables were consistently recorded and reported.

This article reports on the second step, a consensus process with the aim to agree on a basic set of core variables necessary and sufficient to describe a palliative care population. The underlying hypothesis was that it would be possible to define a basic set of descriptors to be universally applied in palliative care research as well as in clinical settings, but that a supplementary, modular approach might be necessary for specific studies and/or diseases other than cancer.

\section{Methods}

This was a five-step international web-based Delphi process conducted between 2 February and 11 August 2011. The study was coordinated from the PRC at the Norwegian University of Science and Technology (NTNU) in collaboration with the EAPC-RN and the project PRISMA.

\section{Size and composition of the panel}

In total, 103 palliative care researchers and clinicians from 35 countries and editors of 14 palliative care journals were invited to participate. As part of the project PRISMA, ${ }^{9,10}$ we tried to identify all chairs in palliative care and palliative medicine in Europe. In countries without such chairs, palliative care researchers or other identified contacts were approached. These individuals were identified from the EAPC, Open Society Institute, UK Hospice Information Service, national associations for palliative care and/or palliative medicine in European countries and a number of international contacts and through literature searches. An additional literature search identified authors who had published on how to describe or classify a palliative care population. Board members of the EAPC and EAPC-RN were also invited to participate.

We received 69 responses from the 117 invited contacts, stating their willingness to participate in the Delphi process. In the first round, information about the participants was collected: country of residence, age, gender, physical location of workplace, number of years working 
Table I. Using the variable patient's performance status as an example, this table shows how the questions were phrased in each round of the Delphi process and the answer options.

\begin{tabular}{|c|c|c|c|}
\hline $\begin{array}{l}\text { Delphi round } \\
\text { number }\end{array}$ & Question & Answer options & Comments from the responders \\
\hline I & $\begin{array}{l}\text { Should the EAPC basic dataset include } \\
\text { the patient's performance status? }\end{array}$ & $\begin{array}{l}\text { [ ] Yes, I agree } \\
\text { [ ] Don't know/Not sure } \\
\text { [ ] No, I don't agree - please } \\
\text { comment: }\end{array}$ & $\begin{array}{l}\text { - Work is required to determine } \\
\text { whether ECOG, Karnofsky and } \\
\text { PPS are equivalent } \\
\text { - Because of changes in time } \\
\text { - Yes if longitudinal database } \\
\text { purposes are aimed }\end{array}$ \\
\hline 2 & $\begin{array}{l}\text { Should the EAPC basic dataset include } \\
\text { the patient's performance status? } \\
\text { Please view the results and read the } \\
\text { COMMENTS from the first round } \\
\text { before making the new selection. }\end{array}$ & $\begin{array}{l}\text { [ ] Strongly agree } \\
\text { [ ] Agree } \\
\text { [ ] Disagree } \\
\text { [ ] Strongly disagree }\end{array}$ & \\
\hline 3 & $\begin{array}{l}\text { There was full agreement (strongly } \\
\text { agree: } 87 \% \text {, agree: } 13 \% \text { ) that the } \\
\text { EAPC basic dataset should include the } \\
\text { patient's performance status. How } \\
\text { should the patient's performance } \\
\text { status be recorded in the EAPC basic } \\
\text { dataset? }\end{array}$ & $\begin{array}{l}\text { [ ] Karnofsky Performance } \\
\text { Status Scale } \\
\text { [ ] WHO/ECOG Performance } \\
\text { Status } \\
\text { [ ] Palliative Performance Scale } \\
\text { [ ] Other - please specify: } \\
\end{array}$ & $\begin{array}{l}\text { - Depends on what is used in } \\
\text { that setting } \\
\text { - Intuitive NRS performance } \\
\text { status (from } 0 \text { to 100) } \\
\text { - Not sure } \\
\text { - ADL, IADL } \\
\text { - Australian Karnofsky } \\
\text { Performance Status as it can be } \\
\text { used in different settings }\end{array}$ \\
\hline 4 & $\begin{array}{l}\text { How should the patient's } \\
\text { performance status be recorded in } \\
\text { the EAPC basic dataset? } \\
\text { Please view the results and read the } \\
\text { COMMENTS from the third round } \\
\text { before making the new selection. }\end{array}$ & $\begin{array}{l}\text { [ ] Karnofsky Performance Status } \\
\text { Scale/Australian Karnofsky } \\
\text { Performance Status } \\
\text { [ ] WHO/ECOG Performance } \\
\text { Status } \\
\text { [ ] Palliative Performance Scale }\end{array}$ & \\
\hline 5 & $\begin{array}{l}\text { How should the patient's } \\
\text { performance status be recorded in } \\
\text { the EAPC basic dataset? } \\
\text { Please view the RESULTS from the } \\
\text { fourth round before making the } \\
\text { new selection and choose between } \\
\text { the two options with the highest } \\
\text { agreement for the fourth round. }\end{array}$ & $\begin{array}{l}\text { [ ] Karnofsky Performance Status } \\
\text { Scale/Australian Karnofsky } \\
\text { Performance Status } \\
\text { [ ] WHO/ECOG Performance } \\
\text { Status }\end{array}$ & \\
\hline
\end{tabular}

NRS: Numerical Rating Scale; ECOG: Eastern Cooperative Oncology Group; PPS: Palliative Performance Scale; WHO: World Health Organization; ADL: activity of daily living; IADL: instrumental activities of daily living.

within palliative care, professional definition (clinician, researcher or both), professional background and name. Non-responders from earlier rounds were excluded from subsequent rounds.

\section{Methodology of the Delphi process}

The Delphi approach engages experts in responding to questions and to give subsequent contributions based on the initial responses. The participants were contacted via e-mail with a link to an online questionnaire using the SelectSurvey.NETv4.066.001 software. ${ }^{14}$

Panellists were asked to fill in the questionnaire on behalf of themselves only. They had 2 weeks to complete each round. A reminder was sent to non-responders after 10 days. The deadline was postponed 1 week in all the rounds. The Delphi coordinators gathered, collated and analysed the data (descriptive statistics) and made additional requests for response based on the findings. The responses were strictly confidential, and data were reported only in aggregate form. Most of the questions were mandatory.

First round. The purpose of the first round was to collect ideas. The research group provided a list of 18 variables, divided between a patient form and a health-care personnel form. The selection was based on a systematic literature review, ${ }^{13}$ analysis of existing minimum datasets for national palliative care databases ${ }^{15-24}$ and the Resident Assessment Instrument for Palliative Care (RAI-PC). ${ }^{25}$ The participants were asked about their level of agreement as to whether the proposed variables should be included in the basic dataset (Table 1). They were also given the opportunity to propose new variables. If $\geq 10 \%$ of the respondents proposed the same new variable, it was 
included in the next Delphi round. The questionnaire for the first Delphi round was pilot tested by 11 experts from our research network.

Second round. The purpose of the second round was to inform the participants about the results of the first round and to rate each variable. The participants were presented with the results from the first round, including the new, added variables and all submitted comments. Based on this information, the participants were asked to rate their level of agreement with each of the 32 proposed variables on the new list.

Third round. The purpose of the third round was to inform about the final list of variables and to collect ideas on how these variables should be assessed and recorded. For each variable, the research group made one or more proposals for how to assess it, based on the same material as above. ${ }^{13,15-25}$ The participants were free to select one of the proposed assessment methods, if considered optimal, or suggest and specify another way to measure the variable. The questionnaire made for this round was pilot tested by five experts from our research network.

Fourth round. The purpose of the fourth round was to inform about the results from the third round and to make a selection on how the variables should be assessed and recorded. The participants were asked to select one alternative for each variable.

Fifth round. The purpose of the fifth round was to inform about the results from the fourth round and to reach consensus on how the remaining variables should be recorded. The participants were asked to choose between the two options with the highest level of agreement from the fourth round.

\section{Statistical analysis}

Consensus was defined as $70 \%$ agreement within the group. Data storage and descriptive statistics were performed using the software SPSS version 19.0.

\section{Ethics}

The Regional Committee for Medical and Health Research Ethics, Central Norway, was contacted. Due to the nature of the study, no application was required.

\section{Results}

\section{The Delphi panel}

The Delphi panel in round 1 consisted of 64 palliative care experts from 30 countries. The background of the expert group is presented in Table 2.
Table 2. Background of the Delphi panel $(n=64)$.

\begin{tabular}{|c|c|}
\hline \multicolumn{2}{|l|}{ Professional background } \\
\hline Basic science & 2 \\
\hline Epidemiology/public health/policy & 5 \\
\hline Medicine, general practice & I \\
\hline Medicine, oncology & 14 \\
\hline Medicine, palliative medicine & 26 \\
\hline Medicine, psychiatry & I \\
\hline Medicine, other & 6 \\
\hline Nursing & 6 \\
\hline Psychology & 1 \\
\hline Social work & 1 \\
\hline Sociology & I \\
\hline \multicolumn{2}{|l|}{ Workplace } \\
\hline Cancer centre & 14 \\
\hline District general hospital & 4 \\
\hline Hospice & 7 \\
\hline Nursing home (institution) & 1 \\
\hline Primary care setting & I \\
\hline Teaching hospital & 23 \\
\hline University campus (not attached to a hospital) & 9 \\
\hline Other & 5 \\
\hline \multicolumn{2}{|l|}{ Professional definition } \\
\hline Clinician & 12 \\
\hline Researcher & 12 \\
\hline Both clinician and researcher & 37 \\
\hline Other & 3 \\
\hline \multicolumn{2}{|l|}{ Gender } \\
\hline Female & 31 \\
\hline Male & 33 \\
\hline \multicolumn{2}{|l|}{ Country } \\
\hline Australia & 1 \\
\hline Austria & 1 \\
\hline Belgium & 3 \\
\hline Bosnia and Herzegovina & 1 \\
\hline Bulgaria & 1 \\
\hline Canada & 2 \\
\hline Croatia & 1 \\
\hline Czech Republic & I \\
\hline Denmark & 1 \\
\hline Finland & 1 \\
\hline France & 2 \\
\hline Georgia & 1 \\
\hline Germany & 4 \\
\hline Greece & 1 \\
\hline Hungary & I \\
\hline Iceland & 2 \\
\hline Ireland & 2 \\
\hline Israel & I \\
\hline Italy & I \\
\hline Netherlands & 6 \\
\hline Norway & 8 \\
\hline Poland & 1 \\
\hline Portugal & 1 \\
\hline Serbia & 1 \\
\hline Slovenia & 1 \\
\hline Spain & 4 \\
\hline Sweden & 2 \\
\hline Switzerland & 1 \\
\hline United Kingdom & 6 \\
\hline United States of America & 5 \\
\hline \multicolumn{2}{|c|}{$\begin{array}{l}\text { Mean number of years working in palliative care }=15.1 \text { years } \text { (range } \\
I-34 \text { years) }\end{array}$} \\
\hline \multicolumn{2}{|c|}{$\begin{array}{l}\text { Participants mean age }=50.4 \text { years, } \text { median age }=51 \text { years }(\text { range: } \\
25-68 \text { years) }\end{array}$} \\
\hline
\end{tabular}




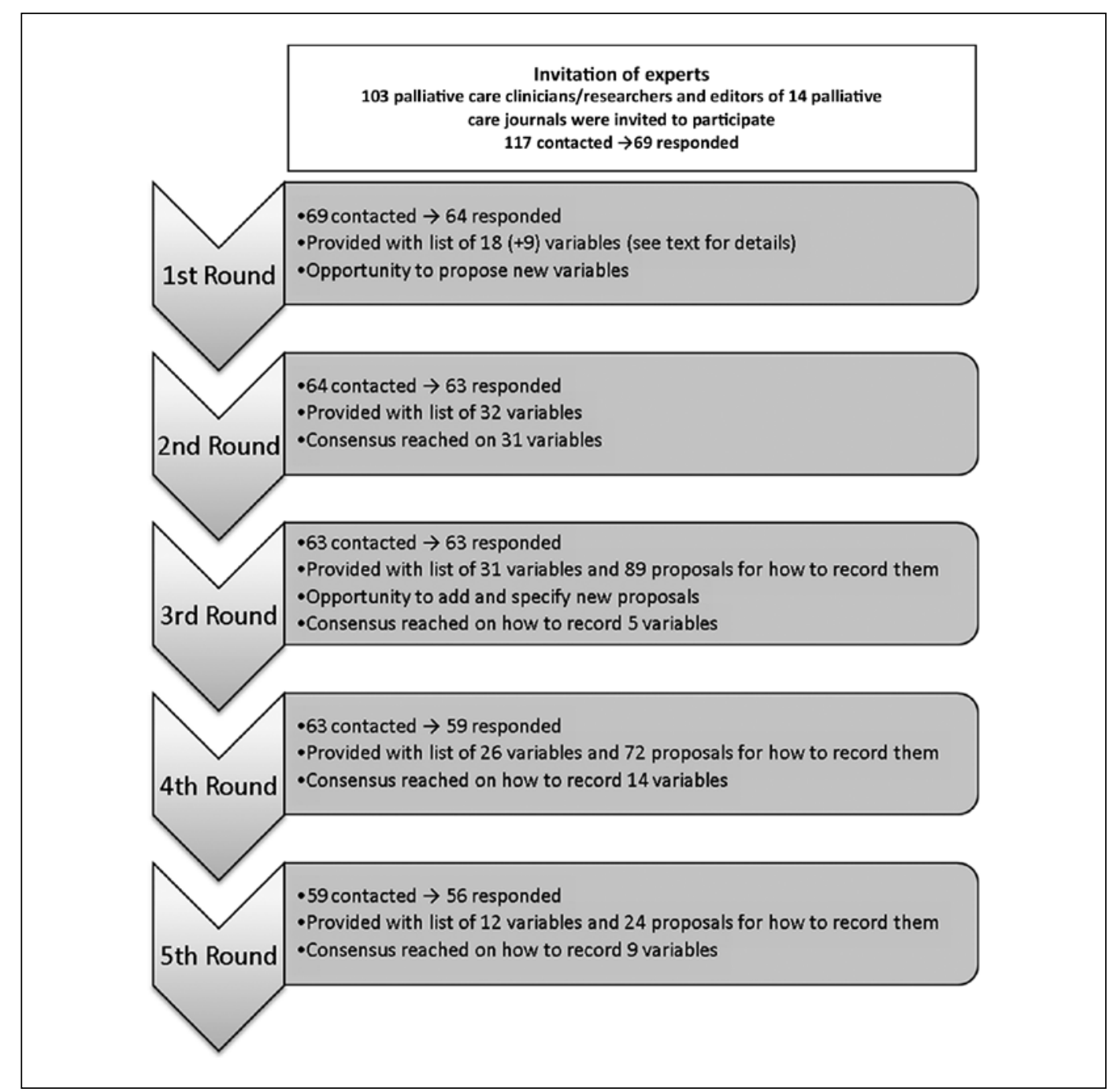

Figure I. Flowchart of the Delphi process to reach consensus on the EAPC basic dataset. EAPC: European Association for Palliative Care.

\section{The Delphi process}

First round. In total, 69 experts were contacted and 64 of them responded. Figure 1 shows a flowchart of the Delphi process. The experts were provided with a list of 18 variables. One of the variables was 'brief symptom assessment'. If the participants agreed that a brief symptom assessment should be part of the dataset, they were presented with a list of the nine symptoms of the revised Edmonton Symptom Assessment System (ESAS-r). ${ }^{26-28}$ Table 3 shows the results from the first and second Delphi rounds. Consensus was reached on 16 items. Three new variables - education, ethnicity and weight loss - and four additional symptoms - insomnia, constipation, vomiting and diarrhoea - were proposed by $\geq 10 \%$ of the respondents.

Second round. In total, 64 experts were contacted and 63 of them responded. The experts were provided with the new list of 32 items (Table 3). A high level of agreement was reached on all items (range: $81 \%-100 \%$ ) except diarrhoea.

Third round. In total, 63 experts were contacted and all responded. They were provided with the list of the 31 agreed variables from round 2 (Table 4 ) together with proposals for how to measure or record each variable (example given in Table 1). Agreement on how to record the following five of the variables was reached: gender, site of metastases, present anticancer treatment, patient's medication and provision of care. Table 4 shows the levels of agreement and how to record the variables.

Fourth round. In total, 63 experts were contacted and 59 responded. The participants were provided with a list of the 26 remaining agreed variables and proposals for how to measure each of them (example shown in Table 1). In 
Table 3. Results from the first two Delphi rounds with level of agreement (\%) for each variable.

\begin{tabular}{|c|c|c|c|c|c|}
\hline & $\begin{array}{l}\text { Variables in first } \\
\text { round }\end{array}$ & $\begin{array}{l}\text { Level of agreement } \\
\text { (\%) in first round }\end{array}$ & $\begin{array}{l}\text { Proposals from } \\
\text { participants in } \\
\text { first round }\end{array}$ & $\begin{array}{l}\text { Variables in second } \\
\text { round }\end{array}$ & $\begin{array}{l}\text { Level of agreement } \\
(\%) \text { in second } \\
\text { round }\end{array}$ \\
\hline \multirow[t]{19}{*}{ Patient form } & Date of birth & 84 & & Date of birth & 92 \\
\hline & Gender & 98 & & Gender & 100 \\
\hline & Living situation & 92 & & Living situation & 98 \\
\hline & $\begin{array}{l}\text { Brief symptom } \\
\text { assessment }\end{array}$ & 97 & & $\begin{array}{l}\text { Brief symptom } \\
\text { assessment: }\end{array}$ & 98 \\
\hline & Anxiety & 85 & & Anxiety & 100 \\
\hline & Appetite & 85 & & Appetite & 100 \\
\hline & Depression & 92 & & Depression & 100 \\
\hline & Drowsiness & 68 & & Drowsiness & 91 \\
\hline & Nausea & 95 & & Nausea & 98 \\
\hline & Pain & 98 & & Pain & 100 \\
\hline & Shortness of breath & 97 & & Shortness of breath & 98 \\
\hline & Tiredness & 85 & & Tiredness & 99 \\
\hline & Well being & 76 & & Well being & 95 \\
\hline & & & Insomnia & Insomnia & 89 \\
\hline & & & Constipation & Constipation & 92 \\
\hline & & & Vomiting & Vomiting & 81 \\
\hline & & & Diarrhoea & Diarrhoea & 65 \\
\hline & & & Education & Education & 84 \\
\hline & & & Ethnicity & Ethnicity & 82 \\
\hline \multirow{14}{*}{$\begin{array}{l}\text { Health-care } \\
\text { personnel form }\end{array}$} & Date of birth & 82 & & Date of birth & 89 \\
\hline & Principal diagnosis & 98 & & Principal diagnosis & 100 \\
\hline & $\begin{array}{l}\text { Date of the principal } \\
\text { diagnosis }\end{array}$ & 77 & & $\begin{array}{l}\text { Date of the principal } \\
\text { diagnosis }\end{array}$ & 91 \\
\hline & $\begin{array}{l}\text { Stage of the cancer } \\
\text { disease }\end{array}$ & 95 & & $\begin{array}{l}\text { Stage of the cancer } \\
\text { disease }\end{array}$ & 97 \\
\hline & Site of metastases & 90 & & Site of metastases & 91 \\
\hline & $\begin{array}{l}\text { Present anticancer } \\
\text { treatment }\end{array}$ & 78 & & $\begin{array}{l}\text { Present anticancer } \\
\text { treatment }\end{array}$ & 81 \\
\hline & $\begin{array}{l}\text { Patient's additional } \\
\text { diagnoses }\end{array}$ & 94 & & $\begin{array}{l}\text { Patient's additional } \\
\text { diagnoses }\end{array}$ & 96 \\
\hline & Medication & 80 & & Medication & 86 \\
\hline & Current weight & 61 & Weight loss & Weight loss & 92 \\
\hline & Height & 48 & & & \\
\hline & $\begin{array}{l}\text { Patient's performance } \\
\text { status }\end{array}$ & 96 & & $\begin{array}{l}\text { Patient's performance } \\
\text { status }\end{array}$ & 100 \\
\hline & Cognitive impairment & 89 & & Cognitive impairment & 89 \\
\hline & Place of care & 95 & & Place of care & 97 \\
\hline & Provision of care & 85 & & Provision of care & 91 \\
\hline
\end{tabular}

this round, consensus was reached on how to record 14 variables (Table 4).

Fifth round. In total, 59 experts were contacted and 56 responded. The experts were provided with a list of the 12 remaining variables and asked to choose between the two proposals with the highest level of agreement from the fourth round. Consensus was reached on how to measure nine variables. Table 4 shows the levels of agreement on how to record the items. Consensus was not reached on how to record the following three variables: ethnicity, vomiting and weight loss. Table 5 shows the two proposals given for these three items and the levels of agreement. For the purpose of pilot testing, the research group decided on how these items should be recorded based on the results and comments from previous Delphi rounds.

\section{Discussion}

We report here on a Delphi process that resulted in consensus on a set of 31 core variables to describe a palliative care cancer population. As far as we are aware, this is the 
Table 4. Variables included in the EAPC basic dataset and how to record them. For each variable, the level of agreement on how to record it, and the Delphi round in which consensus was achieved, are shown.

\begin{tabular}{|c|c|c|c|c|}
\hline & $\begin{array}{l}\text { Variables included in the } \\
\text { EAPC basic dataset }\end{array}$ & How to record each variable & $\begin{array}{l}\text { Delphi round in } \\
\text { which consensus } \\
\text { was reached }\end{array}$ & $\begin{array}{l}\text { Level of } \\
\text { agreement (\%) }\end{array}$ \\
\hline \multirow[t]{17}{*}{ Patient form } & Date of birth & DD.MM.YYYY (Day.Month.Year) & 4 & 81 \\
\hline & Gender & Male ( ), female ( ) & 3 & 98 \\
\hline & Living situation & $\begin{array}{l}\text { Alone ( ), with spouse/partner ( ), with } \\
\text { spouse/partner and children ( ), with } \\
\text { children ( ), with other adult(s) ( ), in an } \\
\text { institution ( ), other ( ) }\end{array}$ & 5 & 70 \\
\hline & Education & $\begin{array}{l}\text { Primary school ( ), secondary school/high } \\
\text { school ( ), college/university ( ) }\end{array}$ & 5 & 77 \\
\hline & Ethnicity & What is your ethnicity? & a & $52^{\mathrm{a}}$ \\
\hline & Anxiety & $\begin{array}{l}\text { Numerical Rating Scale (NRS 0-10); } \\
0=\text { no anxiety to } 10=\text { worst possible anxiety }\end{array}$ & 4 & 80 \\
\hline & Appetite & $\begin{array}{l}\text { Numerical Rating Scale (NRS } 0-10) \\
0=\text { no lack of appetite to } 10=\text { worst } \\
\text { possible lack of appetite }\end{array}$ & 4 & 81 \\
\hline & Depression & $\begin{array}{l}\text { Numerical Rating Scale }(\text { NRS } 0-10) \\
0=\text { no depression to } 10=\text { worst possible } \\
\text { depression }\end{array}$ & 4 & 76 \\
\hline & Drowsiness & $\begin{array}{l}\text { Numerical Rating Scale }(\text { NRS } 0-10) \\
0=\text { no drowsiness to } 10=\text { worst possible } \\
\text { drowsiness }\end{array}$ & 4 & 80 \\
\hline & Nausea & $\begin{array}{l}\text { Numerical Rating Scale (NRS } 0-10 \text { ); } \\
0=\text { no nausea to } 10=\text { worst possible nausea }\end{array}$ & 4 & 80 \\
\hline & Pain & $\begin{array}{l}\text { Numerical Rating Scale (NRS } 0-10) \\
0=\text { no pain to } 10=\text { worst possible pain }\end{array}$ & 4 & 86 \\
\hline & Shortness of breath & $\begin{array}{l}\text { Numerical Rating Scale (NRS } 0-10) \\
0=\text { no shortness of breath to } 10=\text { worst } \\
\text { possible shortness of breath }\end{array}$ & 4 & 81 \\
\hline & Tiredness & $\begin{array}{l}\text { Numerical Rating Scale (NRS } 0-10) \\
0=\text { no tiredness to } 10=\text { worst possible } \\
\text { tiredness }\end{array}$ & 4 & 80 \\
\hline & Well being & $\begin{array}{l}\text { Numerical Rating Scale }(\mathrm{NRS} 0-10) \text {; } \\
0=\text { best well being to } 10=\text { worst possible } \\
\text { well being }\end{array}$ & 4 & 81 \\
\hline & Insomnia & $\begin{array}{l}\text { Numerical Rating Scale (NRS } 0-10) \text {; } \\
0=\text { no insomnia to } 10=\text { worst possible } \\
\text { insomnia }\end{array}$ & 4 & 73 \\
\hline & Constipation & $\begin{array}{l}\text { Numerical Rating Scale (NRS } 0-10) \\
0=\text { no constipation to } 10=\text { worst } \\
\text { possible constipation }\end{array}$ & 5 & 84 \\
\hline & Vomiting & $\begin{array}{l}\text { Numerical Rating Scale (NRS } 0-10) \\
0=\text { no vomiting to } 10=\text { worst possible } \\
\text { vomiting }\end{array}$ & a & $64^{a}$ \\
\hline \multirow{5}{*}{$\begin{array}{l}\text { Health-care } \\
\text { personnel form }\end{array}$} & Date of birth & DD.MM.YYYY. (Day.Month.Year) & 4 & 83 \\
\hline & Principal diagnosis & $\begin{array}{l}\text { International Statistical Classification of } \\
\text { Diseases and Related Health Problems - } \\
\text { I0th Revision. ICD-10 code }\end{array}$ & 4 & 81 \\
\hline & $\begin{array}{l}\text { Date of the principal } \\
\text { diagnosis }\end{array}$ & MM.YYYY. (Month.Year) & 5 & 89 \\
\hline & $\begin{array}{l}\text { Stage of the cancer } \\
\text { disease }\end{array}$ & $\begin{array}{l}\text { Local ( ), locally advanced ( ), metastatic/ } \\
\text { disseminated ( ) }\end{array}$ & 4 & 83 \\
\hline & Site of metastases & $\begin{array}{l}\text { Bone ( ), liver ( ), lung ( ), CNS ( ), } \\
\text { other () }\end{array}$ & 3 & 98 \\
\hline
\end{tabular}


Table 4. (Continued)

\begin{tabular}{|c|c|c|c|}
\hline $\begin{array}{l}\text { Variables included in the } \\
\text { EAPC basic dataset }\end{array}$ & How to record each variable & $\begin{array}{l}\text { Delphi round in } \\
\text { which consensus } \\
\text { was reached }\end{array}$ & $\begin{array}{l}\text { Level of } \\
\text { agreement (\%) }\end{array}$ \\
\hline $\begin{array}{l}\text { Present anticancer } \\
\text { treatment }\end{array}$ & $\begin{array}{l}\text { Radiotherapy ( ), chemotherapy ( ), } \\
\text { hormone therapy ( ), other anticancer } \\
\text { therapy ( ), no anticancer therapy ( ) }\end{array}$ & 3 & 92 \\
\hline $\begin{array}{l}\text { Patient's additional } \\
\text { diagnoses }\end{array}$ & $\begin{array}{l}\text { International Statistical Classification of } \\
\text { Diseases and Related Health Problems - } \\
\text { I0th Revision. ICD-10 code }\end{array}$ & 5 & 86 \\
\hline \multirow[t]{3}{*}{$\begin{array}{l}\text { Stage of the non-cancer } \\
\text { disease }\end{array}$} & $\begin{array}{l}\text { Chronic heart failure (CHF): The } \\
\text { New York Heart Association (NYHA) } \\
\text { Functional classification: NYHA classes: } \\
\text { I ( ), II ( ), III ( ), IV ( ) }\end{array}$ & 5 & 88 \\
\hline & $\begin{array}{l}\text { Chronic obstructive pulmonary disease } \\
\text { (COPD): GOLD classification; stages: I ( ), } \\
\text { II ( ), III ( ), IV ( ) }\end{array}$ & & 79 \\
\hline & $\begin{array}{l}\text { Dementia: FAST scale; stages: I ( ), } 2(\text { ), } \\
3(), 4(), 5(), 6(), 7()\end{array}$ & & 70 \\
\hline Patient's medication & $\begin{array}{l}\text { Standardized list: non-opioid analgesics } \\
(\text { ), opioids ( ), co-analgetics ( ), } \\
\text { corticosteroids ( ), antidepressants (), } \\
\text { antiemetics ( ), neuroleptics ( ), sedatives/ } \\
\text { anxiolytics ( ), drug(s) for acid-related } \\
\text { disorders (), laxatives ( ), antibiotics } \\
(\text { ), diuretics (), heart medication/ } \\
\text { antihypertensives (), other ( ) }\end{array}$ & 3 & 94 \\
\hline Weight loss & $\begin{array}{l}\text { Involuntary weight loss __ } \% \text { and } \\
\text { duration of weight loss } \quad \text { months }\end{array}$ & a & $50^{\mathrm{a}}$ \\
\hline $\begin{array}{l}\text { Patient's performance } \\
\text { status }\end{array}$ & $\begin{array}{l}\text { Karnofsky Performance Status Scale/ } \\
\text { Australian Karnofsky Performance Status }\end{array}$ & 5 & 77 \\
\hline Cognitive impairment & $\begin{array}{l}\text { The patient has cognitive impairment: no } \\
(\text { ), mild ( ), moderate ( ), severe ( ) }\end{array}$ & 5 & 71 \\
\hline Place of care & $\begin{array}{l}\text { Home (), long-term care facilities ( ), } \\
\text { hospice/palliative care unit ( ), } \\
\text { hospital ( ), other ( ) }\end{array}$ & 5 & 77 \\
\hline Provision of care & Inpatient ( ), outpatient ( ), day care ( ) & 3 & 92 \\
\hline
\end{tabular}

EAPC: European Association for Palliative Care; CNS: central nervous system; GOLD: Global Initiative for Chronic Obstructive Lung Disease; FAST: The Functional Assessment Staging Scale.

aConsensus was not achieved.

first internationally anchored minimum dataset for reporting patient characteristics and medical variables in palliative care. The Delphi participants were palliative care experts from Australia, Canada, the United States and 27 countries in Europe. While it was remarkably easy to reach consensus on which variables to include in the dataset, it was more difficult to agree upon how each of them should be measured.

Deciding on what constitutes expertise is critical for the validity of the process. In this study, much work was put into getting an extensive international panel.9,10 Despite this broad approach, we might have missed a number of experts. On the other hand, the panel members had been working on average 15.1 years in palliative care, indicating a skilled, experienced group.
The focus of the present consensus process was patient characteristics and medical variables. In line with this, the Delphi panel was multiprofessional but with a predominance of physicians $(59 \%)$. The limited information on central palliative care domains such as psychosocial and spiritual issues represents a limitation of the dataset. However, there is much less international consensus on how to assess, for example, spiritual distress than physical symptoms, and although all aspects of suffering are intertwined, assessment of spiritual and emotional issues probably needs more cultural considerations and adaptations, also within Europe. A new variable was added if proposed by $\geq 10 \%$ of the respondents, and variables within these domains were proposed by too few participants. Future research is needed to 
Table 5. Variables included in the EAPC basic dataset without consensus on how to record them and the corresponding answer options or scales with highest level of agreement from the fourth Delphi round and the level of agreement in the fifth Delphi round.

Variables included in the EAPC basic dataset

Ethnicity

Vomiting
The two options with the highest levels of agreement from fourth Delphi round provided to the experts in fifth round
Level of agreement (\%) in fifth Delphi round

52
48
64
36
50
50

What is your ethnicity? 52

Caucasian ( ), African ( ), Arab ( ), Asian ( ), $\quad 48$ Other ( )

Numerical Rating Scale (NRS 0-10); $0=$ no

vomiting to $10=$ worst possible vomiting

Number of episodes in the last $24 \mathrm{~h}$

Involuntary weight loss ___ \% and duration of 50

weight loss ___ months

Involuntary weight loss __ $\mathrm{kg}$ (_ \%) and 50

duration of weight loss__ months

EAPC: European Association for Palliative Care.

identify core dataset items for the other domains of palliative care.

The first invitation to participate was sent to 117 individuals, of whom 69 responded. Non-responders were not chased up, and we cannot exclude a certain selection bias. For instance, all the 8 invited experts from Norway participated, while only 1 of 5 invitees from Italy and 6 of 16 from the United Kingdom.

According to acknowledged Delphi guidelines, a response rate of $70 \%$ for each round is required. ${ }^{29}$ In our study, the response rate varied from $100 \%$ to $92 \%$. The overall response rate was $81 \%$. Reasons for dropping out were not reported. The highest number of dropouts was seen in the last two rounds conducted in the summer. We still believe that this first version of the dataset is well founded, as 63 experts participated in the third round and were informed about the final list of variables with one or more proposals for how to assess each of them.

The language, format and contents of the Delphi round questionnaires, especially the proffered lists of response options, represent additional limitations. We tried to minimize this possible bias by making the process utterly transparent, including all comments and remarks from the respondents in the next round. All the participants were encouraged to read every comment before making a new selection.

For defining consensus, $70 \%$ was chosen as the cut-off. In different studies, this ranges from $51 \%$ to $100 \% .{ }^{29,30}$ In the present study, the level of agreement ranged from $70 \%$ to $100 \%$. The level of agreement was lower in the later rounds, focusing on how to record the variables. This probably reflects the plethora of tools and instruments in use, and the lack of international standards and consensus. ${ }^{31}$

The Delphi process started with a list of 18 variables. One of the variables was 'brief symptom assessment'. If the participants agreed that a brief symptom assessment should be part of the EAPC basic dataset, they were presented with an additional list of the nine symptoms of the ESAS-r. ${ }^{26-28}$ The ESAS is widely used in clinical practice; ${ }^{32}$ it measures the most commonly experienced symptoms in cancer patients and is brief and easy to use. ${ }^{33}$ By presenting the ESAS-r in the first round, 97\% of the participants were presented with altogether 27 variables, of which only one was discarded (height) and one changed from 'current weight' to 'weight loss' in the course of the consensus process. It is tempting to interpret this as if we managed to include central variables from the start.

After five rounds, consensus was reached on how to record all variables except three. The research group judged that it was unlikely to achieve consensus in further rounds, and the group decided on how to measure the variables for the purpose of pilot testing the dataset. Ethnicity is a challenging variable and triggered a lot of comments from participants. For the purpose of pilot testing the dataset, an open-ended question will be used: 'what is your ethnicity?'. Vomiting was the second variable without consensus about how to assess it. However, 64\% chose to record it in the same manner as the other symptoms, using a Numerical Rating Scale (NRS) 0-10. This proposal was supported by the research group to secure a uniform approach. ${ }^{34}$ Weight loss was the last variable on which no consensus for assessment was reached. However, the two options on how to record weight loss that received the highest scores were very similar, and the research group decided to follow the recommendation of the European Palliative Care Research Collaborative (EPCRC) Cachexia Guidelines. ${ }^{35}$

Some of the participants expressed their concern about whether it would be too difficult for the most fragile patients to use an NRS and proposed to use a Verbal Categorical Scale (VCS)/Likert scale. This option was added in the next Delphi round; nevertheless, the NRS was the chosen scale. Pilot testing of the dataset will be 
important to judge its feasibility in the frailest patients, and one may test both scale options. It may prove necessary to offer more than one scale option to comply with specific requirements of subgroups of patients or with established practice.

Analysis of existing minimum datasets for national palliative care databases was included in the preparatory work for the present Delphi process. ${ }^{15-24}$ There are major differences between these datasets; some of them are survey constructed, while others collect information on individual patients. Analysis showed that only age, gender and diagnosis were common denominators. These three variables are also included in the only previously published initiative to define a framework of variables to classify a palliative care population. ${ }^{4}$ The published checklis $t^{36}$ contains a limited number of demographic and disease-related variables, making it insufficient for describing the sample in clinical trials. Using the EAPC basic dataset as part of such a checklist for authors would assist in evaluating the external validity of a research report and complement methodology-based checklists of internal validity such as CONSORT for RCTs. ${ }^{37}$

The aim of this process was to obtain a set of common descriptors necessary and sufficient to describe a palliative care cancer population in clinical studies. However, the ideal situation would be to use the same dataset for research, clinical and policy purposes. We realize that supplementary modules may have to be added for specific studies, diseases or objectives. The balance between a dataset that is clear, simple and user-friendly and at the same time providing sufficient information on patient characteristics is delicate. Pilot testing is necessary to evaluate whether the 'right' variables were included and will probably lead to some adjustment of the contents. Many participants stated their willingness to pilot test the dataset, and they will soon be contacted for further action. In the meantime, we strongly encourage researchers and clinicians to start using the dataset, even though it is likely to evolve over time. PDF files of the dataset will be made available on the PRC and EAPC homepages. Development of an electronic version is in progress.

We also regard it a good basis for national databases, supplemented by relevant quality indicators. Finally, the dataset may serve as a very useful checklist for palliative care journals. Used in this way, the EAPC basic dataset will provide a common language and framework for reporting for researchers, clinicians and other palliative care stakeholders. We therefore appeal to editors of palliative care journals, leaders of research groups and national coordinators to take the lead in the use of the EAPC basic dataset in all palliative care settings.

\section{Conclusion}

Palliative care experts from 30 countries were able to reach consensus on a set of 31 core variables to describe a palliative care cancer population. The EAPC basic dataset of patient characteristics and medical variables gives a unique platform for standardizing research and service reporting and could be an important milestone in the development of evidence-based palliative care.

\section{Acknowledgements}

The authors would like to thank the international experts for their participation in this Delphi study. PRISMA members: Gwenda Albers, Barbara Antunes, Ana Barros Pinto, Claudia Bausewein, Dorothee Bechinger-English, Hamid Benalia, Lucy Bradley, Lucas Ceulemans, Barbara A. Daveson, Luc Deliens, Noël Derycke, Martine de Vlieger, Let Dillen, Julia Downing, Michael Echteld, Natalie Evans, Dagny Faksvåg Haugen, Lindsay Flood, Nancy Gikaara, Barbara Gomes, Marjolein Gysels, Sue Hall, Richard Harding, Irene J. Higginson, Stein Kaasa, Jonathan Koffman, Pedro Lopes Ferreira, Johan Menten, Natalia Monteiro Calanzani, Fliss Murtagh, Bregje Onwuteaka-Philipsen, H. Roeline W. Pasman, Francesca Pettenati, Robert Pool, Tony Powell, Miel Ribbe, Katrin Sigurdardottir, Steffen Simon, Franco Toscani, Bart van den Eynden, Jenny van der Steen, Paul Vanden Berghe and Trudie van Iersel.

\section{Declaration of conflicting interests}

None declared.

\section{Funding}

This study was funded by the European Palliative Care Research Centre and Project PRISMA. PRISMA is funded by the European Commission's Seventh Framework Programme (contract number: Health-F2-2008-201655) with the overall aim to coordinate high-quality international research into end-of-life cancer care. PRISMA aims to provide evidence and guidance on best practice to ensure that research can measure and improve outcomes for patients and families. PRISMA activities aim to reflect the preferences and cultural diversities of citizens and the clinical priorities of clinicians and appropriately measure multidimensional outcomes across settings where end-of-life care is delivered. Principal investigator: Richard Harding. Scientific director: Irene J Higginson. Work Package 3 lead: Stein Kaasa.

\section{References}

1. Kaasa S, Torvik K, Cherny N, et al. Patient demographics and centre description in European palliative care units. Palliat Med 2007; 21: 15-22.

2. Laugsand EA, Kaasa S, de Conno F, et al. Intensity and treatment of symptoms in 3,030 palliative care patients: a cross-sectional survey of the EAPC Research Network. $J$ Opioid Manag 2009; 5: 11-21.

3. Borgsteede SD, Deliens L, Francke AL, et al. Defining the patient population: one of the problems for palliative care research. Palliat Med 2006; 20: 63-68.

4. Currow DC, Wheeler JL, Glare PA, et al. A framework for generalizability in palliative care. J Pain Symptom Manage 2009; 37: 373-386.

5. Boisvert $\mathrm{M}$ and Cohen SR. Opioid use in advanced malignant disease: why do different centers use vastly different 
doses? A plea for standardized reporting. J Pain Symptom Manage 1995; 10: 632-638.

6. Caraceni A, Cherny N, Fainsinger R, et al. Pain measurement tools and methods in clinical research in palliative care: recommendations of an Expert Working Group of the European Association of Palliative Care. J Pain Symptom Manage 2002; 23: 239-255.

7. Kaasa $\mathrm{S}$ and Radbruch L. Palliative care research - priorities and the way forward. Eur J Cancer 2008; 44: 1175-1179.

8. Harding R and Higginson IJ. PRISMA: a pan-European coordinating action to advance the science in end-of-life cancer care. Eur J Cancer 2010; 46: 1493-1501.

9. Sigurdardottir KR, Haugen DF, Bausewein C, et al. A panEuropean survey of research in end-of-life cancer care. Support Care Cancer 2012; 20: 39-48.

10. Sigurdardottir KR, Haugen DF, van der Rijt CC, et al. Clinical priorities, barriers and solutions in end-of-life cancer care research across Europe. Report from a workshop. Eur J Cancer 2010; 46: 1815-1822.

11. European Palliative Care Research Centre, http://www. ntnu.edu/prc/prc (2009, accessed 28 June 2013).

12. The European Association for Palliative Care Research Network (EAPC-RN), http://www.eapcnet.eu/Themes/ Research/AbouttheEAPCResearchNetwork.aspx (2010, accessed 28 June 2013).

13. Sigurdardottir KR, Oldervoll LM, Hjermstad MJ, et al. How are palliative care cancer populations characterized in randomized controlled trials? A literature review. J Pain Symptom Manage. Epub ahead of print 6 September 2013. DOI: 10.1016/j.jpainsymman.2013.06.005.

14. classapps. SelectSurvey.NETv4.066.001 software, http:// www.classapps.com/ (2008, accessed 28 June 2013).

15. Australian Institute of Health and Welfare. Admitted Patient Palliative Care National Minimum Data Set: national health data dictionary (version 12, released 16 September 2003). Canberra, http://www.aihw.gov.au/publicationdetail/?id=6442467506 (2003, accessed 28 June 2013).

16. Rys S, Bilsen J, Beguin C, et al. Studie inzake de ontwikkeling van een registratie-instrument voor palliatieve zorg. Ten behoeve van een minimale dataset voor alle settings. Onderzoeksverslag. Federale Overheidsdienst Volksgezondheid, Veiligheid van de Voedselketen en Leefmilieu, Belgie, Maart 2008.

17. Connor SR, Tecca M, LundPerson J, et al. Measuring hospice care: the National Hospice and Palliative Care Organization National Hospice Data Set. J Pain Symptom Manage 2004; 28: 316-328.

18. National Hospice and Palliative Care Organization. National Data Set (NDS), http://www.nhpco.org/performance-measures/national-data-set-nds (accessed 28 June 2013).

19. Stiel S, Pollok A, Elsner F, et al. Validation of the symptom and problem checklist of the German Hospice and Palliative Care Evaluation (HOPE). J Pain Symptom Manage 2012; 43: 593-605.

20. HOPE Clara, https://www.hope-clara.de/ (accessed 28 June 2013).

21. The National Council for Palliative Care (NCPC). The Minimum Data Set (MDS) for specialist palliative care services, http://www.ncpc.org.uk/mds (accessed 28 June 2013).

22. Svenska Palliativregistret. Arsrapport for Svenska Palliativregistret verksamhetsåret 2008. Kalmar: Svenska Palliativregistret, 2009.

23. Kuziemsky CE and Lau F. A comparative analysis of computer based hospice palliative care datasets in Canada. BMC Palliat Care 2008; 7: 1-8.

24. Grønvold M. Dansk Palliativ Database Årsrapport 2010. Bispebjerg Hospital, Copenhagen, http://www.dmcgpal.dk/ default.asp?Action=Details\&; Item=573 (2011, accessed 28 June 2013).

25. Steel K, Ljunggren G, Topinkova E, et al. The RAI-PC: an assessment instrument for palliative care in all settings. $\mathrm{Am}$ J Hosp Palliat Care 2003; 20: 211-219.

26. Bruera E, Kuehn N, Miller MJ, et al. The Edmonton Symptom Assessment System (ESAS): a simple method for the assessment of palliative care patients. $J$ Palliat Care 1991; 7: 6-9.

27. Nekolaichuk C, Watanabe S and Beaumont C. The Edmonton Symptom Assessment System: a 15-year retrospective review of validation studies (1991-2006). Palliat Med 2008; 22: 111-122.

28. Watanabe SM, Nekolaichuk CL and Beaumont C. The Edmonton Symptom Assessment System, a proposed tool for distress screening in cancer patients: development and refinement. Psychooncology 2012; 21: 977-985.

29. Hasson F, Keeney S and McKenna H. Research guidelines for the Delphi survey technique. J Adv Nurs 2000; 32: 1008-1015.

30. Powell C. The Delphi technique: myths and realities. $J A d v$ Nurs 2003; 41: 376-382.

31. Stiel S, Pastrana T, Balzer C, et al. Outcome assessment instruments in palliative and hospice care - a review of the literature. Support Care Cancer 2012; 20: 2879-2893.

32. Cummings G, Biondo PD, Campbell D, et al. Can the global uptake of palliative care innovations be improved? Insights from a bibliometric analysis of the Edmonton Symptom Assessment System. Palliat Med 2011; 25: 71-82.

33. Richardson LA and Jones GW. A review of the reliability and validity of the Edmonton Symptom Assessment System. Curr Oncol 2009; 16: 53-64.

34. Saxby C, Ackroyd R, Callin S, et al. How should we measure emesis in palliative care? Palliat Med 2007; 21: 369 383.

35. Radbruch L, Elsner F, Trottenberg P, et al. Clinical practice guidelines on cancer cachexia in advanced cancer patients. Aachen: Department of Palliative Medicine, European Palliative Care Research Collaborative, http:/www.epcrc.org/ guidelines.php?p=cachexia (2010, accessed 28 June 2013).

36. Currow DC, Tieman JJ, Greene A, et al. Refining a checklist for reporting patient populations and service characteristics in hospice and palliative care research. J Pain Symptom Manage 2012; 43: 902-910.

37. Schulz KF, Altman DG and Moher D. CONSORT 2010 statement: updated guidelines for reporting parallel group randomized trials. Ann Intern Med 2010; 152: 726-732. 